\title{
環境中の発癌性複素環状アミンに関する研究
}

\author{
真 鍋 重 夫
}

東京大学医学部衛生学教室

\section{Carcinogenic Heterocyclic Amines in the Environment}

\author{
Shigeo Manabe \\ Department of Hygiene \& Preventive Medicine, Faculty of Medicine, University of Tokyo, Tokyo
}

\begin{abstract}
The purpose of this report is to summarize data on carcinogenic heterocyclic amines mainly from the aspect of environmental medicine. Since 1977, a new series of heterocyclic amines has been isolated as potent mutagens and they have been shown to be carcinogenic to experimental animals. Among these carcinogens, carcinogenic amino- $\alpha$-carbolines and amino- $\gamma$-carbolines are widely distributed in such components of the environment as airborne particles, rain water, cigarette smoke, diesel exhaust particles and cooked foods. Moreover, most carcinogenic heterocyclic amines are reported to be present in cigarette smoke. These facts suggest that carcinogenic heterocyclic amines are likely to be ubiquitous environmental pollutants. These results also support the hypothesis that carcinogenic heterocyclic amines may be formed through combustion of various materials such as food, grass and petroleum.
\end{abstract}

Key words: Carcinogens, Heterocyclic amines, Environmental pollutants. 発癌物質, 複素環状アミン, 環境污染物質

\section{1.はじめに}

環境中には多数の発癌物質の存在が知られているが， 従来知られていた発癌物質とは異なる一群の類似化学構 造を有する発癌物質がアミノ酸や蛋白の熱分解物や加熱 食品中に存在することが主として国立癌センター研究所 の杉村らにより明らかにされた ${ }^{1 \sim 4)}$ 。1977年の発癌性卜 リプトファン熱分解物の発見以来, 現在までにアミノ酸 や蛋白の熱分解物あるいは，加熱食品中に比較的強力な 変異原性を有し, 複素環状アミンに属する物質が 10 数種 類報告されている ${ }^{3 \sim 5)}$ 。この中で，動物に対する発癌性 が確立しているのは, 表 1 に示した10種類の複素環状ア ミンであり ${ }^{6 \sim 8)}$, 変異原性発癌性複素環状アミンあるい は発癌性複素環状アミンと呼ばれている ${ }^{2 \sim 4)}$ 。これらの 発癌物質は複雑な化学名を有するため通常表 1 に示すご とく略省名で呼ばれている。これらの発癌性複素環状了 ミンは, 最初にアミノ酸や蛋白の熱分解物ないし加熱処
理食品中にその存在が明らかにされたため, 最近まで食 品由来発癌物質 (Dietary Carcinogens) と呼ばれて来た が, これらの発癌物質の一部(Trp-P-1, Trp-P-2, $\mathrm{A} \alpha \mathrm{C}$, $\mathrm{MeA} \alpha \mathrm{C})$ については, 食品以外に, 大気, 雨水などの一 般環境中の存在が明らかにされ ${ }^{9213)}$, 更に, 発癌性複素 環状アミン 10 種のうち 8 種についてはタバコ煙中の存在 が証明されており10,11,14 16)，発癌性複素環状アミンを 食品由来発癌物質と呼ぶことは適切でない状況となって (る13)。

一方, 発癌性複素環状アミンに属する発癌性トリプト ファン熱分解物 (Trp-P-1, Trp-P-2)については, 発癌 性以外にけいれん誘発作用 ${ }^{17}$, 18) やドーパミン, セロト ニン代謝を強力に阻害する作用を有し 18 21), 神経毒と して考えられつつあり，注目されている22)。また，七 トが実際に種々の発癌性複素環状アミンに暴露されてい ることが確実となっており 23 30), これら発癌性複素環 状アミンのヒト健康への影響を本格的に検討すべき時期 
Table 1 Carcinogenic heterocyclic amines isolated from cooked foods andpyrolysates of amino acids and proteins.

\begin{tabular}{|c|c|c|c|c|}
\hline \multicolumn{2}{|r|}{ Heterocyclic amines } & \multirow{2}{*}{$\begin{array}{l}\text { Year of } \\
\text { discovery }\end{array}$} & \multicolumn{2}{|c|}{ Carcinogenicity } \\
\hline Abbreviation & Chemical Name & & Mouse & Rat \\
\hline $\operatorname{Trp}-\mathrm{P}-1$ & 3-amino-1,4-dimethyl- $5 \mathrm{H}$-pyrido $[4,3$ - $\mathrm{b}]$ indole & 1977 & Liver & Liver \\
\hline Trp-P-2 & 3-amino-1-methyl-5H-pyridp $[4,3$-b $]$ indole & 1977 & Liver & Liver \\
\hline Glu-P-1 & 2-amino-6-methyldipyrido $[1,2$-a:3',2'-d $]$ imidazole & 1978 & $\begin{array}{l}\text { Liver } \\
\text { Blood vessel }\end{array}$ & $\begin{array}{l}\text { Liver, Intestine } \\
\text { Zymbal and clitoral glands }\end{array}$ \\
\hline Glu-P-2 & 2-aminodipyrido $\left[1,2-\mathrm{a}: 3^{\prime}, 2^{\prime}\right.$-d $]$ imidazole & 1978 & $\begin{array}{l}\text { Liver } \\
\text { Blood vessel }\end{array}$ & $\begin{array}{l}\text { Liver, Intestine } \\
\text { Zymbal and clitoral glands }\end{array}$ \\
\hline $\mathrm{A} \alpha \mathrm{C}$ & 2 -amino-9H-pyrido $[2,3$-b $]$ indole & 1978 & $\begin{array}{l}\text { Liver } \\
\text { Blood vessel }\end{array}$ & $\mathrm{NR}^{*}$ \\
\hline $\mathrm{MeA} \alpha \mathrm{C}$ & 2-amino-3-methyl-9H-pyrido $[2,3$-b $]$ indole & 1978 & $\begin{array}{l}\text { Liver } \\
\text { Blood vessel }\end{array}$ & $\mathrm{NR}^{*}$ \\
\hline $\mathrm{IQ}$ & 2-amino-3-methylimidazo $[4,5-\mathrm{f}]$ quinoline & 1980 & $\begin{array}{l}\text { Liver, Lung } \\
\text { Forestomach }\end{array}$ & $\begin{array}{l}\text { Liver, Intestine, Skin } \\
\text { Zymbal and clitoral glands }\end{array}$ \\
\hline MeIQ & 2-amino-3,4-dimethylimidazo $[4,5$-f $]$ quinoline & 1980 & $\begin{array}{l}\text { Liver } \\
\text { Forestomach }\end{array}$ & $\begin{array}{l}\text { Liver, Intestine } \\
\text { Oral cavity, Zymbal gland }\end{array}$ \\
\hline MeIQx & 2 -amino-3, 8-dimethylimidazo $[4,5$-f $]$ quinoxaline & 1981 & Liver, Lung & $\begin{array}{l}\text { Liver, Zymbal gland } \\
\text { Clitoral gland }\end{array}$ \\
\hline PhIP & 2-amino-1-methyl-6-phenylimidazo $[4,5$-b $]$ pyridine & 1986 & Lymphoma & Intestine \\
\hline
\end{tabular}

*Not reported.

に達している。本稿では, 日本衛生学会奨励賞受賞講演 の内容をもとに発癌性複素環状アミンの環境中の分布を 中心に研究の現状を衛生学的見地から述べた。

\section{2. 発 癌 性}

発癌性複素環状アミンは, すべて前発癌物質 (Procarcinogen)であり，チトクロームP-450タイプP-448などに より代謝活性化されて究極発癌物質 (Ultimate Carcinogen)

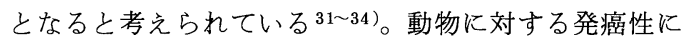
関しては表 1 に示したごとく，PhIPを除いて主として 肝癌を生ずる6 8)。PhIPは, 他の発癌性複素環状アミン とは異なり, $\mathrm{CDF}_{1}$ マウスに対しては, 主としてリンパ 腫を生じ肝癌の発生が見られず7)，また，発癌性物質に 感受性の高い無アルブミン血症ラット(長瀬)に対して小 腸, 大腸に腺癌を生ずる点で8), 特徵がある。発癌性複 素環状アミンの $\mathrm{TD}_{50}$ (一生涯食べ続けた場合に $50 \%$ の動 物に腫瘍を誘発する 1 日投与量) は，マウスにおいて 2.7 $\sim 31.3 \mathrm{mg} / \mathrm{kg} /$ 日と報告されており ${ }^{35)}, \mathrm{TD}_{50}$ からは発 癌性は強くないと言える。しかし， ラットのTD 50 では, 例えばTrp-P-1の場合 $0.1 \mathrm{mg} / \mathrm{kg} /$ 日と報告されており ${ }^{35)}$, マウスの $\mathrm{TD}_{60}$ の約100分の 1 となっており，動物実験に 基づく $\mathrm{TD}_{50}$ から，ヒトに対する発癌性を評価すること は, 問題であろら。これら発癌性複素環状アミンのヒト における発癌性の評価は, 疫学的研究が必須であること
を強調したい36)。

\section{3. 環境中の分布}

発癌性複素環状アミンのうち, 環境中の分布に関して

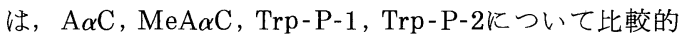
知見が蓄積されている。これらについて表 2 および 3 に 最新のデータも加えてまとめた。

表 2 に示すごとく, 杉村らのグループにより, Trp-P-1, $\operatorname{Trp}-\mathrm{P}-2$ が, 加熱食品中に比較的多量に存在するとの報 告がなされていたが37)38), 食品中のTrp-P-1, Trp-P-2 の含量に関しては, 杉村らのグループより報告されたデー 夕に疑問があるとする報告がなされた ${ }^{39,40)}$ 。特に, Felton らはTrp-P-1, Trp-P-2は, まったく検出されなかった と報告した ${ }^{40)}$ 。 Trp-P-1, Trp-P-2が, 食品中に存在す るのかぞうかについて最近鋭敏な高速液体クロマトグラ フによる測定法を用いて検討したところ ${ }^{41)}$ ，加熱食品 中のTrp-P-1, Trp-P-2含量は, $0.1 \mathrm{ng} / \mathrm{g}$ 以下であると の結論を得たが，この結果は，ガスクロマトグラフィー 法によるMurrayらの結果と矛盾しないと考它られる

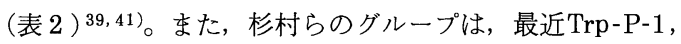
Trp-P-2の加熱食品中の含量は, $0.25 \mathrm{ng} / \mathrm{g}$ 以下と修正 して報告しているが35), 測定方法, 検体数, 調理方法 等の詳細が不明のため表 2 には加えなかった。

一方, Trp-P-1, Trp-P-2は, 表 2 に示すごとく, 大 
Table 2 Distribution of carcinogenic tryptophan pyrolysis products in the environment

\begin{tabular}{|c|c|c|c|}
\hline Environmental element & $\begin{array}{l}\text { Trp-P-1 } \\
\text { mean value }\end{array}$ & $\begin{array}{l}\text { Trp-P-2 } \\
\text { mean value }\end{array}$ & References \\
\hline \multicolumn{4}{|l|}{ Foodstuffs } \\
\hline Broiled sun-dried sardine & $13.3 \mathrm{ng} / \mathrm{g}$ & $13.1 \mathrm{ng} / \mathrm{g}$ & Yamaizumi et al. (1980) \\
\hline Broiled beef & 53.5 & $\mathrm{NR}^{\mathrm{a}}$ & Yamaguchi et al. (1980) \\
\hline $\begin{array}{l}\text { Broiled or fried meat } \\
\text { (lamb, pork, beef and chicken) }\end{array}$ & NR & $<0.1$ & Murray et al. (1987) \\
\hline $\begin{array}{l}\text { Broiled or fried fish } \\
\text { (asrdine and sun-dried sardine) }\end{array}$ & NR & $<0.1$ & Murray et al. (1987) \\
\hline $\begin{array}{l}\text { Fried meat } \\
\text { (beef, chicken and pork) }\end{array}$ & $\mathrm{ND}^{\mathrm{b}}$ & ND & Felton et al. (1988) \\
\hline Broiled sardine & $10.9 \mathrm{pg} / \mathrm{g}$ & $98.0 \mathrm{pg} / \mathrm{g}$ & Manabe et al. (1991) \\
\hline Broiled beef & 8.4 & 20.6 & \\
\hline Broiled pork & 11.5 & 27.9 & \\
\hline Soy sauce & $4.2 \mathrm{ng} / 1$ & $13.3 \mathrm{ng} / 1$ & \\
\hline $\begin{array}{l}\text { Cigarette smoke } \\
\text { (mainstream smoke) }\end{array}$ & $0.38 \mathrm{ng} / \mathrm{cig}$ & $0.95 \mathrm{ng} / \mathrm{cig}$ & Manabe \& Wada (1990) \\
\hline \multicolumn{4}{|c|}{ Airborne particles (August 1988 to October 1988) } \\
\hline Tokyo & $0.34 \mathrm{pg} / \mathrm{m}^{3}$ air & $0.29 \mathrm{pg} / \mathrm{m}^{3}$ air & Manabe et al. (1989) \\
\hline \multicolumn{4}{|l|}{ Rain water (November 1988) } \\
\hline Tokyo & $468 \mathrm{pg} / 1$ & $174 \mathrm{pg} / 1$ & Manabe et al. (1989) \\
\hline \multicolumn{4}{|l|}{ Automobile exhaust particles } \\
\hline $\begin{array}{l}\text { NIES standard materials } \\
(\text { NIES No.8) }\end{array}$ & ND & $65 \mathrm{pg} / \mathrm{g}$ & Manabe et al. (1991) \\
\hline $\begin{array}{l}\text { Diesel exhaust particles } \\
\text { (Nissan TD-42) }\end{array}$ & $80 \mathrm{pg} / \mathrm{g}$ & $538 \mathrm{pg} / \mathrm{g}$ & \\
\hline
\end{tabular}

${ }^{\mathrm{a}}$ Not reported. ${ }^{\mathrm{b}}$ Not detected.

c Standard materials obtained from the National Institute for Environmental Studies, Tsukuba, Japan (NIES).

気や雨水などの一般環境中に存在するばかりでなく, タ バュ煙で污染された室内空気中にも存在し，その含量は， 大気中含量の数倍以上になることも明らかになっている 9, 10)。

同様に表 3 に $\alpha \mathrm{C}, \mathrm{MeA} \alpha \mathrm{C}$ (発癌性アミノ- $\alpha$-カルボ リン)の環境中の分布を示した。Trp-P-1, Trp-P-2と同 様に食品以外に, 大気, 雨水などの一般環境中に広く分 布していることが明らかになっている13)。1988年 7 月 から 1 年間の大気 (東京大学屋上)中濃度は, $\mathrm{A} a \mathrm{Cでは,} 0.70$ $\mathrm{pg} / \mathrm{m}^{3}$ でTrp-P-1, Trp-P-2, MeA $\alpha \mathrm{C}$ りも高值を示し た 13)。また， $\mathrm{A} \alpha \mathrm{C}, \mathrm{MeA} \alpha \mathrm{C}$ をに，11月から 3 月まで の冬期に大気中濃度の著しい上昇が認められた ${ }^{13)}$ 。一 万, Trp-P-1, Trp-P-2 と同様に, $\mathrm{A} \alpha \mathrm{C}, \mathrm{MeA} \alpha \mathrm{C}$ ををに, ディーゼル排ガス中にこれらの存在が確認された ${ }^{12)}$ 。 この事実より大気中のこれら発癌物質の発生源の 1 つは,
ディーゼル排ガスであると考穴られる。をた，冬期の $\mathrm{A} \alpha \mathrm{C}$ ， $\mathrm{MeA} \alpha \mathrm{C}$ の大気中濃度の上昇は，暖房に伴らものではな いかと推定している ${ }^{13)}$ 。

以上のごとく, 発癌性複素環状アミンのうち $\mathrm{A} \alpha \mathrm{C}$, $\mathrm{MeA} \alpha \mathrm{C}$, Trp-P-1, Trp-P-2については, 広く一般環境 中に分布しており, 食品由来発癌物質ではなく環境発癌 物質 (Environmental Carcinogens)と呼ぶべきであろう 13,22)。さらに, 表 4 に示すごとく, 発癌性複素環状ア ミン10種のうち 8 種までが，タバュ煙中に存在すること が明らかにされておら 10,11,14 16), 発癌性複素環状了ミ ンは，多環芳香族炭化水素等之同様に物質の燃焼過程て

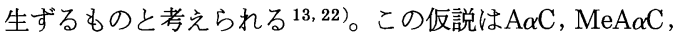
Trp-P-1, Trp-P-2などが，ディーゼル排ガス中に検出 される事実によっても支持されるものと考觉られる12)。 
Table 3 Distribution of carcinogenic amino- $\alpha$-carbolines in the environment.

\begin{tabular}{|c|c|c|c|}
\hline \multirow[b]{2}{*}{ Environmental element } & \multicolumn{2}{|c|}{ Amino- $\alpha$-carbolines } & \multirow[b]{2}{*}{ References } \\
\hline & $\mathrm{A} \alpha \mathrm{C}$ & $\mathrm{MeA} \alpha \mathrm{C}$ & \\
\hline \multicolumn{4}{|l|}{ Foodstuffs } \\
\hline Grilled beef & $650 \mathrm{ng} / \mathrm{g}$ & $64 \mathrm{ng} / \mathrm{g}$ & Matsumoto et al. (1981) \\
\hline Grilled chicken & 180 & 15 & Matsumoto et al. (1981) \\
\hline Grilled chinese mushroom & 47 & 5.4 & Matsumoto et al. (1981) \\
\hline Grilled onion & 1.5 & $\mathrm{ND}^{\mathrm{a})}$ & Matsumoto et al. (1981) \\
\hline Broiled sardine & $25 \mathrm{pg} / \mathrm{g}$ & $14 \mathrm{pg} / \mathrm{g}$ & Manabe et al. (1991) \\
\hline Broiled beef & 26 & ND & Manabe et al. (1991) \\
\hline Soy sauce & $6.6 \mathrm{ng} / 1$ & $7.3 \mathrm{ng} / 1$ & Manabe et al. (1991) \\
\hline \multicolumn{4}{|l|}{ Cigarette smoke (mainsteram smoke) } \\
\hline & $\begin{array}{l}100 \mathrm{ng} / \mathrm{cig} \\
42\end{array}$ & $\begin{array}{l}18 \mathrm{ng} / \mathrm{cig} \\
2.5\end{array}$ & $\begin{array}{l}\text { Yoshida \& Matsumoto }(1980) \\
\text { Manabe \& Wada }\end{array}$ \\
\hline \multicolumn{4}{|l|}{ Airborne Particles (July 1988-July 1989) } \\
\hline Tokyo & $0.70 \mathrm{pg} / \mathrm{m}^{3} \mathrm{air}$ & $0.07 \mathrm{pg} / \mathrm{m}^{3}$ air ${ }^{\mathrm{b})}$ & Manabe et al. (1991) \\
\hline \multicolumn{4}{|l|}{ Rain water (July 1988-July 1989) } \\
\hline Tokyo & $81 \mathrm{pg} / 1$ & $13 \mathrm{pg} / 1$ & Manabe et al. (1991) \\
\hline \multicolumn{4}{|l|}{ Soil (June 1989) } \\
\hline Tokyo & $6.5 \mathrm{pg} / 1$ & ND & Manabe et al. (1991) \\
\hline \multicolumn{4}{|l|}{ Automobile Exhaust Particles } \\
\hline NIES STANDARD Materials $\left(\right.$ No.8) ${ }^{c}$ ) & $0.66 \mathrm{ng} / \mathrm{g}$ & $0.05 \mathrm{ng} / \mathrm{g}$ & Manabe et al. (1991) \\
\hline \multicolumn{4}{|l|}{ Diesel Exhaust Particles (Isuzu 4BDI) } \\
\hline Low-speed cruise condition & 3.1 & ND & Manabe et al. (1991) \\
\hline High-speed cruise condition & 51 & 2.1 & Manabe et al. (1991) \\
\hline
\end{tabular}

a) Not detected b) Not detected from July to September in 1988.

c) Standard materials obtained from NIES (National Institute for EnvironmentalStudies, Tsukuba, Japan).

Table 4 Summary of carcinogenic heterocyclic amines and some poly nuclear aromatic hydrocarbons in cigarette mainstream smoke

\begin{tabular}{lccl}
\hline \multicolumn{1}{c}{ Carcinogens } & $\begin{array}{c}\text { Range } \\
\text { (ng/cig) }\end{array}$ & $\begin{array}{l}\text { Mean } \\
(\mathrm{ng} / \mathrm{cig})\end{array}$ & \multicolumn{1}{c}{ References } \\
\hline Carcinogenic heterocyclic amines & & \\
$\mathrm{A} \alpha \mathrm{C}$ & $25-260$ & 100 & Yoshida \& Matsumoto (1980) \\
& $28-48$ & 42.0 & Manabe et al. (1990) \\
$\mathrm{MeA} \alpha \mathrm{C}$ & $9-37$ & 18 & Yoshida \& Matsumoto (1980) \\
& $2.0-3.0$ & 2.5 & Manabe et al. (1990) \\
$\mathrm{IQ}$ & - & 0.26 & Yamashita et al. (1986) \\
Trp-P-1 & $0.29-0.48$ & 0.38 & Manabe et al. (1990) \\
Trp-P-2 & $0.82-1.1$ & 0.95 & Manabe et al. (1990) \\
Glu-P-1 & $0.37-0.89$ & 0.66 & Kanai et al. (1990) \\
Glu-P-2 & $0.25-0.88$ & 0.63 & Kanai et al. (1990) \\
PhIP & $11-23$ & 16 & Manabe et al. (1991) \\
Polynuclear aromatic hydrocarbons & & IARC (1986) \\
Anthracene & $23-240$ & - & IARC (1986) \\
Benzo [a] anthracene & $4-76$ & - & IARC (1986) \\
Benzo [a] fluorene & $41-180$ & - & IARC (1986) \\
Benzo [a] pyrene & $15-27$ & 20 & \\
\hline
\end{tabular}




\section{4. 暴露レベルの評価}

発癌性複素環状アミンのヒトでの暴露レベル評価は， これら発癌物質のヒト健康への影響を知るためには必須 のことであり，いくつかの試みが始められている。私共 は, 腎不全透析患者の透析液を用いた暴露レベルの推定 から始め, 現在では赤血球中へモグロビンと付加体を形 成した発癌物質量を測定することにより，暴露レベルを 評価する方向に進んでいる ${ }^{36,42,43)}$ 。

研究開始初期は，腎不全患者をモデルとして暴露レべ ル評価を試みた 23 26)。しかし，ヒトが実際に発癌性複 素環状アミンに暴露されていることを明らかとするため には，都合のよいモデルと言えたが，特殊なモデルであ り, 一般人の暴露レベル評価方法とはなり得ず, 現在動 物実験により暴露レベル評価方法を開発している42,43)。

動物実験によると, Trp-P-1, Glu-P-1などの発癌性 複素環状アミンは, 経口投与されたものの一部が, 赤血 球中のへモグロビンと結合し，長時間赤血球中にとどま ることが明らかになっている42,43)。また，へモグロビ ンと結合した発癌物質の量は, 経口的投与量に比例して おり，暴露レベル評価方法として有用であることが明ら かになっている ${ }^{43)}$ 。実際に，Trp-P-1, Trp-P-2は，七 卜赤血球中に存在することを確認しており，量一反応関 係がどの範囲で成立しているかを明らかにできれば暴露 レベル評価方法として有用であると考学られる。一部の

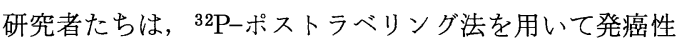
複素環状アミンの暴露レベル評価方法の開発を行ってお り，少量の血液を用いて暴露レベルを評価できれば，有 用であり，研究の進展が期待される44,45)。

\section{5.おわりに}

1977年以後, アミノ酸や蛋白の熱分解物や加熱食品中 に発見された発癌性複素環状アミンの環境中の分布を中 心に概説し，これら発癌物質の特徵や発生機序に対する 仮説を述べた。また，これら発癌物質の暴露レベル評価 方法の開発の現状についても触れたが，今後はこれら発 癌性複素環状アミンの発生機序の解明とヒトでの暴露レ ベル評価が重要な課題であると考㝋られる。

\section{謝辞}

本研究は, 1985年 7 月から, 東京大学医学部衛生学教 室で行われたものであり, 研究の遂行には和田攻教授を はじめとして教室員の御協力を頂いた。また，奨励賞を 頂いた上に，このような機会を与えて頂いた日本衛生学
会の諸先生方に深甚の謝意を表します。本研究の一部は 文部省科学研究費 (02454198) おちよび佐川がん研究助成振 興財団の援助により行われた。

\section{文献}

1) Sugimura, T., Kawachi, T., Nagao, M., Yahagi, T., Seino, Y., Okamoto, T., Shudo, K., Kosuge, T. , Tsuji, K., Wakabayashi, K., litaka, Y. and Itai, A.: Mutagenic principle(s) in tryptophan and phenylalanine pyrolysis products, Proc. Jpn. Acad., 53B, 59-61 (1977).

2 ) Sugimura, T. and Sato, S.: Mutagens-carcinogens in foods, Cancer Res. , 43(Suppl.), 2415-2421 (1983) .

3 ) Sugimura, T. : Past, present and future of mutagens in cooked foods, Environ. Health Perspect. , 67, 5-10 (1986)

4) Sugimura, T. : Studies on environmental chemical carcinogenesis in Japan, Science, 233, 312-318 (1986) .

5 ) Felton, J.S., Knize, M.G., Shen, N.H., Lewis, P.R., Anderson, B.D. ,Happe, J. and Hatch, F.T. : The isolation and identification of a new mutagen from fried ground beef; 2-amino-1-methyl-6-phenylimidazo $[4,5-\mathrm{b}]$ pyridine (PhIP), Carcinogenesis, 7, $1081-1086$ (1986).

6 ) Sugimura, T.: Carcinogenicity of mutagenic heterocyclic amines formed during cooking process, Mutat. Res., 150, 33-41 (1985).

7 ) Esumi, H., Ohgaki, H. , Kohzen, E. , Takayama, S. and Sugimura, T. : Induction of lymphoma in $\mathrm{CDF}_{1}$ mice by the food mutagen, 2-amino-1-methyl-6phenylimidazo $[4,5-b]$ pyridine, Jpn. J. Cancer Res., 80, 1176-1178 (1989).

8 ) Ochiai, M., Ogawa, K., Wakabayashi, K., Sugimura, T. , Nagase, S., Esumi, H. and Nagao, M. : Induction of intestinal adenocarcinomas by 2-amino-1-methyl-6-phenylimidazo [4,5-b] pyridine in Nagase analbuminemic rats, Jpn. J. Cancer Res. , 82, 363-366 (1991).

9 ) Manabe, S., Uchino, E. and Wada, O.: Carcinogenic tryptophan pyrolysis products in airborne particles and rain water, Mutat. Res., 226, 215-221 (1989).

10) Manabe, S. and Wada, O.: Carcinogenic tryptophan pyrolysis products in cigarette smoke condensate and cigarette smoke-polluted indoor air, Environ.Pollut. , 
64, 121-132 (1990).

11) Manabe, S., Wada, O. and Kanai, Y.: Simultaneous determination of amino- $\alpha$-carbolines and amino- $\gamma$ carbolines in cigarette smoke condensate by highperformance liquid chromatography, J. Chromatogr. , 529, 125-133 (1990).

12) Manabe, S., Izumikawa, S., Asakuno, K., Wada, O. and Kanai, Y. : Detection of carcinogenic amino- $\alpha$ carbolines and amino- $\gamma$-carbolines in diesel-exhaust particles, Environ. Pollut., 70, 255-265 (1991).

13) Manabe, S., Izumikawa, S., Asakuno, K., Wada, O., Morita, M. and Suzuki, H. : Occurence of carcinogenic amino- $\alpha$-carbolines in some environmental samples, Environ. Pollut., (in press).

14) Yoshida, D. and Matsumoto, T. : Amino- $\alpha$-carbolines as mutagenic agents in cigarette smoke condensate, Cancer Lett. , 10, 141-149 (1980).

15) Yamashita, M., Wakabayashi, K., Nagao, M., Sato, S., Yamaizumi, Z., Takahashi, M., Kinae, N. , Tomita, I. and Sugimura, T. : Detection of 2-amino-3-methylimidazo [4, 5-f] quinoline in cigarette smoke condensate, Jpn. J. Cancer Res. , 77, 419-422 (1986).

16) Kanai, Y., Wada, O. and Manabe, S. : Detection of carcinogenic glutamic acid pyrolysis products in cigarette smoke condensate, Carcinogenesis, 11, 1001-1003 (1990).

17) Muraki, T., Yamazoe, Y. and Kato, R.: Inhibition of benzodiazepin and GABA receptor binding by amino- $\gamma$-carbolines and other amino acid pyrolysate mutagens, Eur. J. Pharmacol., 98, 35-44 (1984).

18) Kanai, Y., Wada, O. and Manabe, S.: Antagonism of $\gamma$-aminobutyric acid A receptor-mediated responses by amino- $\gamma$-carbolines, J. Pharmacol. Exp. Ther. , 252, 1269-1276 (1990).

19) Manabe, S., Kanai, Y., Ishikawa, S. and Wada, O. : Carcinogenic tryptophan pyrolysis products: potent inhibitors of type A monoamine oxidase and the platelet response to 5 -hydroxytryptamine, J. Clin. Chem. Biochem., 26, 265-270 (1988).

20) Ichinose, H. , Ozaki, N., Nakahara, D., Naoi, M., Wakabayashi, K., Sugimura, T. and Nagatsu, T. : Effects of heterocyclic amines in food on dopamine metabolism in nigro-strial dopaminergic neurons,
Biochem. Pharmacol., 37, 3289-3295 (1988).

21) Naoi, M., Takahashi, T., Ichinose, H., Wakabayashi, K., Sugimura, T. and Nagastu, T.: Reduction of enzyme activity of tyrosine hydroxylase and aromatic L-aminoacid decarboxylase in clonal pheochromocytoma PL12h cells by carcinogenic heterocyclic amines, Biochem. Biophys. Res. Commun. , 157, 494-499 (1988).

22) Manabe, S., Wada, O. and Kanai, Y.: Pharmacotoxicological asepcts of carcinogenic tryptophan pyrolysis products in the environment, J. Environ . Sci. Health (in press).

23) Yanagisawa, H., Manabe, S., Kitagawa, Y., Ishikawa, S. , Nakajima, K. and Wada, O.: Presence of 2-amino-3, 8-dimethylimidazo [4, 5-f] quinoxaline (MeIOx) in dialysate from patients with uremia, Biochem. Biophys. Res. Commun., 138, 1084-1089 (1986).

24) Manabe, S., Yanagisawa, H., Guo, S-B., Abe, S., Ishikawa, S. and Wada, O.: Detection of Trp-P-1 and Trp-P-2, carcinogenic tryptophan py rolysis products, in dialysis fluid of patients with uremia, Mutat. Res., 179, 33-40 (1987).

25) Manabe, S., Yanagisawa, H., Ishikawa, S., Kitagawa, Y., Kanai, Y. and Wada, O.: Accumulation of 2-amino-6-methyldipyrido [1, 2-a:3', 2'-d] imidazole and 2-amino-dipyrido [1, 2-a:3', 2'-d] imidazole, carcinogenic glutamic acid pyrolysis products in plasma of patients with uremia, Cancer Res., 47, 6150-6155 (1987).

26) Yanagisawa, H., Manabe, S. and Wada, O.: Detection of IQ-type heterocyclic amines in dialysis fluid of uremic patients treated by peritoneal dialysis, Jpn. J. Nephrol. , 29, 1153-1159 (1987).

27) Kanai, Y., Manabe, S. and Wada, O.: In vitro and in vivo $\mathrm{N}$-acetylation of carcinogenic glutamic acid pyrolysis products in humans, Carcinogenesis, 9 , 2179-2184 (1988).

28) Manabe, S. and Wada, O.: Analysis of human plasma as an exposure level monitor for carcinogenic tryptophan pyrolysis products, Mutat. Res., 209, 33-38 (1988).

29) Ushiyama, H. , Wakabayashi, K., Nagao, M. and Sugimura, T. : Detection of heterocyclic amines in 
human urine, Proc 48th Jpn. Cancer Assoc. , Nagoya p.54 (1989).

30) Manabe, S. and Wada, O.: Identification of carcinogenic tryptophan pyrolysis products in human bile by high-performance liquid chromatography, Environ. Mutagen., 15, 229-235 (1990).

31) Hashimoto, Y., Shudo, K. and Okamoto, T. : Activation of a mutagen, 3-amino-1-methyl-5Hpyrido $[4,3-\mathrm{b}]$ indole. Identification of 3-hydroxy amino-1-methyl-5H-pyrido $[4,3-\mathrm{b}]$ indole and its reaction with DNA, Biochem. Biophys. Res. Commun., 96, 335-362 (1980).

32) Hashimoto, Y., Shudo, K. and Okamoto, T. : Deoxyribonucleic acid modification by mutagenic 3-amino-1-methyl-5H-pyrido [4, 3-b] indole; The chemical events, Chem. Pharm. Bull., 32, 4300-4308 (1984).

33) Kato, R.: Metabolic activation of mutagenic heterocyclic aromatic amines from protein pyrolysates, CRC Crit. Rev. Toxicol., 16, 307-349 (1984).

34) Yamazoe, Y., Abu-Zeid, M., Yamauchi, K. and Kato, R.: Metabolic activation of pyrolysate arylamines by human liver microsomes: possible involvement of a P-488- $\mathrm{H}$ type cytochrome P-450, Jpn. J. Cancer Res. (Gann), 79, 1159-1167 (1988).

35）長尾美奈子：食物とがん遺伝子発現, 臨床栄養, 77, 879-884 (1990).

36）真鍋重夫, 和田 攻：環境中の発癌性トリプトファ 熱分解物に関する研究の現状と今後の問題, 日衛 誌, 44, 821-830 (1989).

37) Yamaizumi, Z., Shiomi, T., Kasai, H. , Nishimura, S., Takahashi, Y., Nagao, M. and Sugimura, T. : Detection of potent mutagens, Trp-P-1 and Trp-P-2, in broiled fish, Cancer Lett. , 9, 75-83 (1980).
38) Yamaguchi, K., Shudo, K., Okamoto, T., Sugimura, T. and Kosuge, T. :Presence of 3-amino-1, 4-dimethyl $-5 \mathrm{H}$-pyrido $[4,3-\mathrm{b}]$ indole in broiled beef, Gann, 71, 745-746 (1980).

39) Murray, S., Gooderham, N.J., Barnes, V.F., Boobis, A.R. and Davies, D.S.: Trp-P-2 is not detectable in cooked meat and fish, Carcinogenesis, 8, 937-940 (1987).

40) Felton, J.S., Knize, M.G., Shen, N.H., Wu, R. and Becher, G.: Mutagenic heterocyclic imidazoamines in cooked foods, In King, C.M. , Romano, L.J. and Schuetzle, D. (eds.) "Carcinogenic and Mutagenic Responses to Aromatic Amine and Nitroarenes", pp.73-83, Elsevier, New York (1988).

41) Manabe, S., Wada, O. and Kanai, Y.: Carcinogenic amino- $\alpha$-carbolines and amino- $\gamma$-carbolines in cooked foods and soy sauce, Environ. Sci., 1, 11-19 (1991).

42) Manabe, S. and Kanai, Y. and Wada, O.: Exposure level monitor of 3-amino-1, 4-dimethyl-5H-pyrido $[4,3-b]$ indole, a dietary carcinogen, in rabbits, Environ. Mutagen., 14, 34-41 (1989).

43) Yin, Y., Wada, O. and Manabe, S. : Exposure level monitor of a carcinogenic glutamic acid pyrolysis products in rabbits, Mutat. Res. , 215, 107-113 (1989).

44) Gupta, R.C., Reddy, M.V. and Randerath, K. : 32P-Postlabeling analysis of non-radioactive aromatic carcinogen-DNA addcuts, Carcinogenesis , 3, 10811092 (1982)

45) Perera, F.P.: The signif icance of DNA and protein adducts in human biomonitoring studies, Mutat. Res., 205, 255-269 (1988).

（受付 1991年 5 月 15 日 受理 1991年 6 月 25 日） 